Research Paper

\title{
Study of in Vitro and in Vivo Bone Formation in Compo- site Cryogels and the Influence of Electrical Stimulation
}

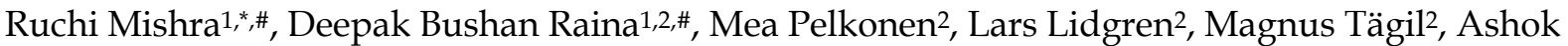 \\ Kumar1, $^{\circledR}$ \\ 1. Department of Biological Sciences and Bioengineering, Indian Institute of Technology Kanpur, Kanpur-208016, UP, India \\ 2. Department of Orthopedics, Clinical Sciences, Lund University, Lund-221 85, Sweden \\ \# First two authors have equal contribution in this work. \\ * Current affiliation- Department of Plastic Surgery, The Ohio State University, Columbus, Ohio-43210 \\ $\triangle$ Corresponding author: Ashok Kumar, Department of Biological Sciences and Bioengineering, Indian Institute of Technology Kanpur, Kanpur- \\ 208016, UP, India. E-mail: ashokkum@iitk.ac.in; Tel: +91-512-2594051; Fax: +91-512-2594010
}

() 2015 Ivyspring International Publisher. Reproduction is permitted for personal, noncommercial use, provided that the article is in whole, unmodified, and properly cited. See http:/ /ivyspring.com/terms for terms and conditions.

Received: 2015.07.04; Accepted: 2015.08.08; Published: 2015.10.04

\begin{abstract}
This work studies osteoinduction and bone conduction in polyvinyl alcohol-tetraethylorthosilicate-alginate-calcium oxide (PTAC) biocomposite cryogels along with the synergistic effect of electrical stimulation. In vitro osteoinduction of $\mathrm{C} 2 \mathrm{C} 12$ myoblast towards osteogenic lineage is demonstrated through alkaline phosphatase assay, scanning electron microscopy and energy dispersive X-ray spectroscopy. These results were followed by in vivo implantation studies of PTAC biocomposite cryogel scaffolds in the bone conduction chamber model depicting bone formation after 24 days based on immunohistological staining for osteogenic markers, i.e., collagen type I (Col I), osteocalcin (OCN), osteopontin (OPN) and bone sialoprotein (BSP). Further, osteogenic differentiation of murine mesenchymal stem cells was studied with and without electrical stimulation. The q-PCR analysis shows that the electrically stimulated cryogels exhibit $\sim 6$ folds higher collagen type I and $\sim 10$ folds higher osteopontin mRNA level, in comparison to the unstimulated cryogels. Thus, PTAC biocomposite cryogels present osteoinductive and osteoconductive properties during in vitro and in vivo studies and support osteogenic differentiation of mesenchymal stem cells under the influence of electrical stimulation.
\end{abstract}

Key words: Cryogel, bone formation, osteoinduction, bone conduction chamber, electrical stimulation

\section{Introduction}

Bone tissue engineering aims at regeneration of bone tissue, which is lost due to fracture, tumor, congenital defects, injuries caused during sports, etc [1]. It is one of the highly researched domains of tissue engineering mainly due to a high occurrence rate of bone defects [1-3]. These defects can be treated either by replacement or regeneration based methods. Replacement methods include autografts (which acts as a gold standard), allografts, xenografts and prosthetics; whereas, regeneration based methods include tissue-engineered biomaterials, growth factors and cells [2-4]. Due to the complications associated with bone grafts and prosthetic materials, various ceramic and/or polymeric biomimetic materials based on tissue engineering strategies have evolved $[5,6]$.

According to one of the earliest definitions by Friedenstein, osteoinduction is "the induction of undifferentiated inducible osteoprogenitor cells that are not yet committed to the osteogenic lineage to form osteoprogenitor cells" [7]. Exhibiting this property is very beneficial for bone tissue engineered biomaterials [8]. Some of the other properties which are important for bone tissue engineered biomaterials are osteoconductivity- to allow ingrowth of the surrounding bone tissue, osseointegrativity- property of forming a physical bond with the surrounding bone 
tissue, bioactivity- ability to form a bioactive hydroxyapatite-like layer on coming in contact with body fluids and, bioresorbability- to resorb without formation of any toxic products in the body $[9,10]$. We developed PTAC biocomposite cryogels keeping all these properties in mind and tested them at various levels to find out whether they exhibited these properties. We have previously studied the in vitro physical and biological properties of this cryogel along with studying its in vivo bone regeneration potential in a critical sized cranial bone defect model in rats [11, 12]. However, the osteoinductive properties of these cryogels have not been explored. Thus, due to the presence of significant amount of bioactive glass, which has previously been associated with osteoinductive properties, it is important to study these cryogels for exploring the possibility of exhibiting the property of 'osteoinductivity' [13-15]. Bone formation in PTAC biocomposite cryogel through bone chamber model was studied to analyze the bone forming potential of PTAC biocomposite cryogels. On the other hand, we also studied the effect of electrical stimulation on the differentiation of mesenchymal stem cells (MSCs) on these cryogels since it has been reported to have a positive effect on osteogenesis [16]. The presence of a PTAC biocomposite cryogel along with electric stimulation may have a synergistic effect on osteogenic differentiation of MSCs. Therefore, in this paper, we present the results obtained during the in vitro and in vivo study of bone formation on PTAC biocomposite cryogels under the influence of intrinsic or extrinsic stimulatory factors.

\section{Materials and Methods}

\section{Study design}

In vitro studies were performed in two ways: 1 ) study of osteoinduction of $\mathrm{C} 2 \mathrm{C} 12$ myoblasts on PTAC biocomposite cryogel surface, and, 2) study of osteogenic differentiation of murine mesenchymal stem cells on PTAC biocomposite cryogel surface in presence/absence of electrical stimulation. In vivo studies were performed in a bone conduction chamber model in accordance with the guidelines provided by the Swedish national and regional animal ethics committees.

\section{Materials}

Col I monoclonal antibody was procured from Assay biotechnology (CA, U.S.A). Mouse monoclonal antibody against OCN and rabbit monoclonal OPN antibody was obtained from Abcam (Cambridge, U.K). Rabbit BSP polyclonal antibody was a kind gift from Dr. Viveka Tillgren (BMC, Lund University). All antibodies were specific to react with rat target proteins. Anti rabbit horseradish peroxidase (HRP) con- jugate secondary antibody and 3, 3'-diaminobenzidine (DAB) was supplied by Vectorlabs (CA, U.S.A) while anti-mouse secondary antibody was obtained from KPL antibodies (Maryland, U.S.A). Pentobarbital sodium (Apotekets Productions and Laboratory, Sweden), stesolid (Actavis AB, Sweden) and streptocilin vet (Boehringer Ingelheim Vetmedica, Malmö, Sweden) were procured from the local pharmacy. Animals for experimental purposes were purchased from Taconic (Denmark). Dulbecco's Modified Eagle's Medium (DMEM), 3-(4,5-dimethylthiazol-2-yl)-2,5-diphenyltetrazolium bromide (MTT), penicillin-streptomycin antibiotic, sigma fast $\mathrm{pNPP}$ tablets and trypsin-EDTA from Sigma Aldrich (MA, U.S.A). Sodium bicarbonate was obtained from Ranbaxy (Delhi, India); Fetal bovine serum and Gibco ${ }^{\mathrm{TM}}$ Antibiotic-Antimycotic (100X), liquid from Invitrogen (NY, U.S.A); cDNA synthesis kit from Fermentas (Vilnius, Lithuania); SYBR green from Takara Bio (Shiga, Japan); and primers for Col I, OPN and $\beta$-actin gene markers from Eurofins MWG operon, (Ebersberg, Germany). All the other materials used were of high purity grade.

\section{Scanning electron microscopy (SEM) and en- ergy dispersive $\mathbf{X}$-ray spectroscopy (EDX)}

Three cryogel samples were processed for scanning electron microscopy at different time points using following steps: 1) cells were washed twice in phosphate buffered saline (PBS) for 5 minutes each; 2) cell fixation was performed in $2.5 \%$ glutaraldehyde for 4 hours; and 3) Dehydration in graded alcohol series, i.e., $20 \%, 40 \%, 60 \%, 80 \%$ and $100 \%$ ethanol for 5 minutes at each step. Once dehydrated, these samples were sputter coated with gold in a sputter coater machine (Vacuum Tech). After gold coating, these samples were analysed in a scanning electron microscope (FEI Quanta 200 SEM microscope) working under high vacuum and high voltage $(20 \mathrm{kV})$ at a sample spot size of $3.5 \mu \mathrm{m}$. The spot size used for energy dispersive X-ray spectroscopy analysis was 3 $\mu \mathrm{m}$.

\section{Real-time PCR (q-PCR)}

The fold change in the mRNA expression of osteogenic markers, Col I and OPN was analyzed via q-PCR analysis. Three cryogel samples per time point were analyzsed for this study. The steps involved were as follows: 1) RNA isolation was performed through phenol-chloroform extraction method using TRIzol reagent. 2) RNA was quantified in $n g / \mu l$ using picodrop instrument and the readings were ascertained to be pure via confirmation of 260/280 ratio. 3) The obtained RNA was converted to cDNA through the activity of reverse transcriptase enzyme along 
with other kit components of cDNA kit. 4) cDNA was further amplified using SYBR green chemistry to relatively quantify the mRNA levels of osteopontin and osteocalcin using specific primers. Here, beta-actin ( $\beta$-actin) acted as a housekeeping gene as well as control gene for normalization of mRNA levels. The quantification of mRNA was performed using 2(- $\Delta$ $\Delta \mathrm{C}(\mathrm{T}))$ method [17].

\section{Cell culture}

The cryogel samples were sterilized in following steps prior to cell culture studies: a) Ultraviolet (U.V.) light incubation for $30 \mathrm{~min}$; b) 70\% ethanol treatment for $30 \mathrm{~min}$; c) incubation in PBS supplemented with $5 \%$ antibiotic-antimycotic solution (100X) for $30 \mathrm{~min}$; and d) media incubation for 1 hour. The C2C12 cell lines used for this study were cultured in DMEM media supplemented with $10 \%$ fetal bovine serum (FBS) and $1 \%$ penicillin-streptomycin (antibiotic) and seeded at a density of $1.5 \times 10^{5}$ cells $/ \mathrm{ml}$. For the electrical stimulation studies, the mesenchymal stem cells were isolated from the tibia and femur bones of mice. Briefly, the tibia and femur were collected from the anaesthetized mice in PBS containing 2\% antibiotic and muscles still attaching around the bones were carefully removed. These bones were now transferred to DMEM media containing $1 \%$ antibiotic. The extreme ends of the bones were cut in order to obtain a hollow tube containing bone marrow. These were transferred to a petriplate containing fresh DMEM high glucose media supplemented with fetal bovine serum $(20 \%)$. Now, bone marrow tissue was flushed from the hollow cavities of the femur and tibia using $10 \mathrm{ml}$ disposable syringe. All the bone marrow tissue collected in this way was transferred to a T-25 flask (Corning Inc.). These flasks were incubated for a week under constant monitoring for any contamination. At this point, most of the adherent mesenchymal stem cells have attached, thereafter, media was changed and cells were cultured to $\sim 80 \%$ confluence before sub-culturing. The mesenchymal stem cells (as obtained) for electrical stimulation experiment were seeded at passage 3 and at a cell density of $1 \times 10^{4}$ cells $/ \mathrm{ml}$. Media was switched to osteogenic media containing $100 \mathrm{nM}$ dexamethasone, $10 \mathrm{mM}$ $\beta$-glycerophosphate and $50 \quad \mu \mathrm{g} / \mathrm{ml}$ 2-phosphate-ascorbic acid at day 2 of mesenchymal stem cell culture on PTAC biocomposite cryogels.

\section{Electrical stimulation set-up}

For electrical stimulation studies, an electrical stimulation set-up was assembled in the sterile environment of a cell culture hood. The anode and cathode wires were connected to the power supply unit. These wires were connected at the other end to the copper electrodes. These electrodes were fixed at the ends of a sterile 6 well plate. Thereafter, electric current was passed through the cryogel samples in presence of PBS as the conducting medium. The stimulation regime consisted of an electrical field at field strength of $2 / 3$ volts $/ \mathrm{cm}$, which is employed for $1 \mathrm{~min}$ each at a frequency of every alternate day. A sample size of 3 was used for each analysis related to electrical stimulation studies.

\section{3-(4,5-Dimethylthiazol-2-yl)-2,5-diphenyltetra zolium bromide (MTT assay)}

MTT assay was performed in order to quantify the proliferation of cells cultured on the PTAC biocomposite cryogels. MTT solution was prepared by adding $5 \mathrm{mg} / \mathrm{ml}$ MTT reagent in serum-free DMEM high glucose media. The assay was performed briefly in following steps: 1) Three cryogel samples per time point were washed in PBS for 5 min; 2) to these samples, MTT solution was added and incubation was performed for $4 \mathrm{~h}$ in cell culture incubator; 3) MTT solution was aspirated out and dimethyl sulphoxide (DMSO) was added as a solvent for dissolving the formazan crystal produced by cellular activity; 4) incubation with DMSO was performed for $10 \mathrm{~min}$ in cell culture incubator, and, 5) the absorbance of the purple coloured end product as developed was read in a $\mathrm{UV}-\mathrm{Vis}$ spectrophotometer machine at $570 \mathrm{~nm}$ wavelength.

\section{Alkaline phosphatase assay}

Sigma fast pNPP tablet set was used for this study. This tablet set contains the substrate for alkaline phosphatase enzyme, i.e, $p a$ ra-nitrophenylphosphate (pNPP) along with Tris buffer and magnesium chloride. Three cryogel samples per time point were washed twice in PBS for 5 min each before adding the substrate solution. After adding the substrate, the cryogel samples were incubated for $30 \mathrm{~min}$. Thereafter, the absorbance was read in a spectrophotometer at $405 \mathrm{~nm}$.

\section{Bone chamber}

The bone chamber is made of titanium and consists of two hollow semi cylinders with a threaded conical base held together by a hexagonal screw cap (Supplementary Fig. 1). The inner diameter of the chamber is $2 \mathrm{~mm}$ and the height $7 \mathrm{~mm}[18,19]$. One of the half cylinders contains two holes for cellular infiltration. An osteoconductive material is placed inside the chamber and the chamber is screwed into the proximal tibia. The ingrowth openings will be situated at the level of the subcortical bone, leaving the interior of the chamber in contact with metaphyseal bone and bone marrow cells. 


\section{Scaffold preparation and surgical procedure}

PTAC cryogel scaffolds were prepared, [11] and, dried scaffolds were cut manually using a biopsy punch of $2 \mathrm{~mm}$ diameter. Each cylinder was cut to a height of $4 \mathrm{~mm}$ and processed for sterilization. Scaffolds were sterilized using an increasing ethanol gradient with overnight incubation in $70 \% \mathrm{EtOH}$ and dehydration with absolute EtOH for $1 \mathrm{~h}$. Thereafter, the scaffolds were washed with phosphate buffered saline (PBS) three times and incubated at $37{ }^{\circ} \mathrm{C}$ overnight to ensure that they were dry before the surgery.

Six Sprague-Dawley rats of 6 weeks age were anesthetized using an intra peritoneal (I.P) injection of $15 \mathrm{mg} / \mathrm{ml}$ pentobarbital sodium and $2.5 \mathrm{mg} / \mathrm{ml}$ of diazepam. Prior to surgery, the animals intramuscularly received Streptocillin as antibiotic prophylaxis and the right hind legs were shaved and sterilized with iodine. An approximately $1.5 \mathrm{~cm}$ long parapatellar incision was made on the right leg and the proximal tibia was exposed. A $2.0 \mathrm{~mm}$ hole was manually drilled anterior to the medial collateral ligament, and the chamber containing the scaffolds was screwed onto the bone. The chamber was positioned subcutaneously throughout the experiment to minimize the risk of infection. The animals had free access to food and water. After 24 days, the animals were sacrificed by an intraperitoneal overdose of pentobarbital sodium. Chambers were harvested, opened and the scaffolds were immediately placed in $4 \%(\mathrm{w} / \mathrm{v})$ formaldehyde for overnight fixation.

\section{Histological analysis}

The fixed samples were demineralized in $10 \%$ $(\mathrm{w} / \mathrm{v})$ ethylenediaminetetraaceticacid (EDTA) for $12 \mathrm{~h}$ for paraffin sectioning. Samples were dehydrated in increasing $\mathrm{EtOH}$ gradient and xylene for $20 \mathrm{~min}$ each and placed in liquid paraffin at $60{ }^{\circ} \mathrm{C}$ overnight followed by another paraffin change for $2 \mathrm{~h}$. The samples were embedded in paraffin and sectioned to $5 \mu \mathrm{m}$ thickness using a microtome. The sections were allowed to adhere to lysine coated slides for $24 \mathrm{~h}$ and stained using either hematoxylin and eosin (H\&E) or a combination of hematoxylin, eosin, alcian blue, orange- $\mathrm{G}$ and phloxine- $\mathrm{B}$.

\section{$H$ \& E Staining}

Sections were de-paraffinized using xylene and rehydrated using decreasing EtOH gradient until 90\% $\mathrm{EtOH}$ and washed for $5 \mathrm{~min}$ in running water. The hydrated sections were nuclear stained using hematoxylin for $5 \mathrm{~min}$ and then counterstained using eosin for $2 \mathrm{~min}$. Thereafter, the sections were dehydrated in increasing $\mathrm{EtOH}$ gradient and finally cleared in $x y-$ lene for $10 \mathrm{~min}$. These sections were initially allowed to dry and finally they were mounted using xylene based mounting medium.

Alcian blue, hematoxylin, orange-G, phloxine-B, eosin staining

De-paraffinized sections were placed in acid alcohol $(70 \% \mathrm{EtOH}$ and $38 \% \mathrm{HCl}$ by volume) for $30 \mathrm{sec}$ and placed in alcian blue, hematoxylin working solution consisting of $1 \%(\mathrm{w} / \mathrm{v})$ of alcian blue in $100 \mathrm{ml}$ of hematoxylin solution for $30 \mathrm{~min}$. The slides were washed gently in distilled water and differentiated in acid alcohol for $5 \mathrm{sec}$ followed by rinsing in distilled water with three changes. These slides were placed in $0.5 \%(\mathrm{w} / \mathrm{v})$ of ammonium water for $15 \mathrm{sec}$ and again rinsed in distilled water with two changes followed by $\mathrm{EtOH}(95 \%)$ treatment for $1 \mathrm{~min}$. In the end, the slides were placed in eosin/ orange $G /$ phloxine $B$ solution ( $1 \%$ phloxine $B, 2 \%$ orange $G$ ) for $2 \mathrm{~min}$. Eventually the slides were dehydrated with increasing $\mathrm{EtOH}$ gradient from 90 to $100 \%$ for 2 min each with 2 changes and cleared with xylene for $5 \mathrm{~min}$ before mounting. New bone is stained bright orange, while, cartilage matrix and cells are stained blue using this mixed stain.

\section{Alizarin red staining for neo-tissue minerali- zation}

The sections were de-paraffinized as mentioned earlier and allowed to rehydrate in distilled water for 5 min. Rehydrated tissue samples were then immersed for $4 \mathrm{~min}$ in alizarin red working solution consisting of $1 \%(\mathrm{w} / \mathrm{v})$ alizarin red in distilled water. Excess stain was taken off by placing the slide in running water for $1 \mathrm{~min}$ followed by 20 dips in a mixture of acetone and xylene (1:1) and finally dipping in xylene for 5 min each with two changes. Dried slides were later mounted with xylene based mounting medium. The stain forms a complex with matrix calcium to produce orange to red shades.

\section{Immunohistochemical analysis for osteogenic markers}

Immunohistochemical analysis was performed by studying the expression of bone related markers like collagen type I (COL1), osteocalcin (OCN), osteopontin (OPN) and bonesialoprotein (BSP). Antigen retrieval buffer was prepared by mixing $0.05 \%(\mathrm{w} / \mathrm{v})$ bovine trypsin and $0.01 \%(\mathrm{w} / \mathrm{v})$ calcium chloride in deionized water at $\mathrm{pH}$ 7.6. The sections were first de-paraffinized and rehydrated followed by incubation in antigen retrieval buffer for $30 \mathrm{~min}$ at $37^{\circ} \mathrm{C}$ and rinsing in deionized water. Endogenous peroxidase activity was quenched using 3\% (v/v) hydrogen peroxide and the sections were briefly rinsed in PBST. Tissue sections were incubated in $5 \%(\mathrm{v} / \mathrm{v})$ goat serum for $1 \mathrm{~h}$ at room temperature to block non-specific 
antibody interaction. All antibodies were prepared at a dilution of 1:200 in phosphate buffered saline with $0.1 \%(\mathrm{v} / \mathrm{v})$ tween-20 (PBST) and sections were incubated with respective primary antibodies for a period of $1 \mathrm{~h}$ at room temperature followed by washing in PBST five times for $5 \mathrm{~min}$ each. HRP conjugate secondary antibody solution was used as per supplier's guidelines and sections were incubated for $1 \mathrm{~h}$ at room temperature followed by PBST washes for 5 times at 5 min each. DAB reagent was prepared as per supplier's guidelines and sections were incubated for $5 \mathrm{~min}$ in the reagent until a prominent brown color was visible. Sections were counterstained with hematoxylin for $5 \mathrm{~min}$ and mounted as mentioned above. A negative antibody control was also used by following the same procedure except for the addition of primary antibody. In this method, cells and matrix containing target proteins produce a prominent brown color.

\section{Animal ethics and statistical analysis}

All animal experiments were carried out in accordance with the guidelines of the Swedish regulatory authority for animal experiments (Jordbruksverket, approval number M25-13). All experiments were carried out in triplicates $(n=3)$, unless otherwise specified and all the statistical analyses were performed using two-tailed t-test assuming unequal variances.

\section{Results}

The results are divided into three main sections, i.e., 1) osteoinduction of $\mathrm{C} 2 \mathrm{C} 12$ myoblasts cultured on PTAC biocomposite cryogels, 2) in vivo bone formation in a bone conduction chamber model, 3) osteogenic differentiation of murine mesenchymal stem cells on PTAC biocomposite cryogel surface in presence/absence of electrical stimulation.

\section{Osteoinduction of $\mathrm{C} 2 \mathrm{C} 12$ myoblasts on PTAC biocomposite cryogels}

\section{Cell proliferation}

Cell proliferation was determined by MTT assay as shown in Fig. 1(a). The absorbance values mimic a polynomial of $2^{\text {nd }}$ degree and $2^{\text {nd }}$ order showing a decreasing trend. Upon further analysis, it was observed that absorbance values for cell proliferation do not show any statistically significant change with respect to previous time point until day 11 . While, as we go forward we observe statistically significant decrease between time points; from day 11 to day 15 $(\mathrm{p}=0.003)$ and from day 15 to day $20(\mathrm{p}=0.015)$ (Fig. 1(a)). In the two-dimensional (2D) control, i.e., C2C12 cell grown on tissue cultured polystyrene (TCPS), the cell proliferation initially increased till day 15 and started declining from day 15 to day 30.

\section{Alkaline phosphatase (ALP) assay}

This assay uses direct correlation between amount of alkaline phosphatase (ALP) enzyme present and absorbance values obtained. It can be observed in Fig. 1(b) that the ALP readings were negligible in the case of two-dimensional (2D) control. Whereas, in the case of $\mathrm{C} 2 \mathrm{C} 12$ seeded PTAC biocomposite cryogels, the cells show a significant increase in growth as indicated by the increase in absorbance, as we move from day 3 to day $7(p=0.0008)$ and then from day 7 to day $15(\mathrm{p}=0.0006)$ and finally it reduces significantly as we move from day 15 to day $30(\mathrm{p}=0.0002)$.

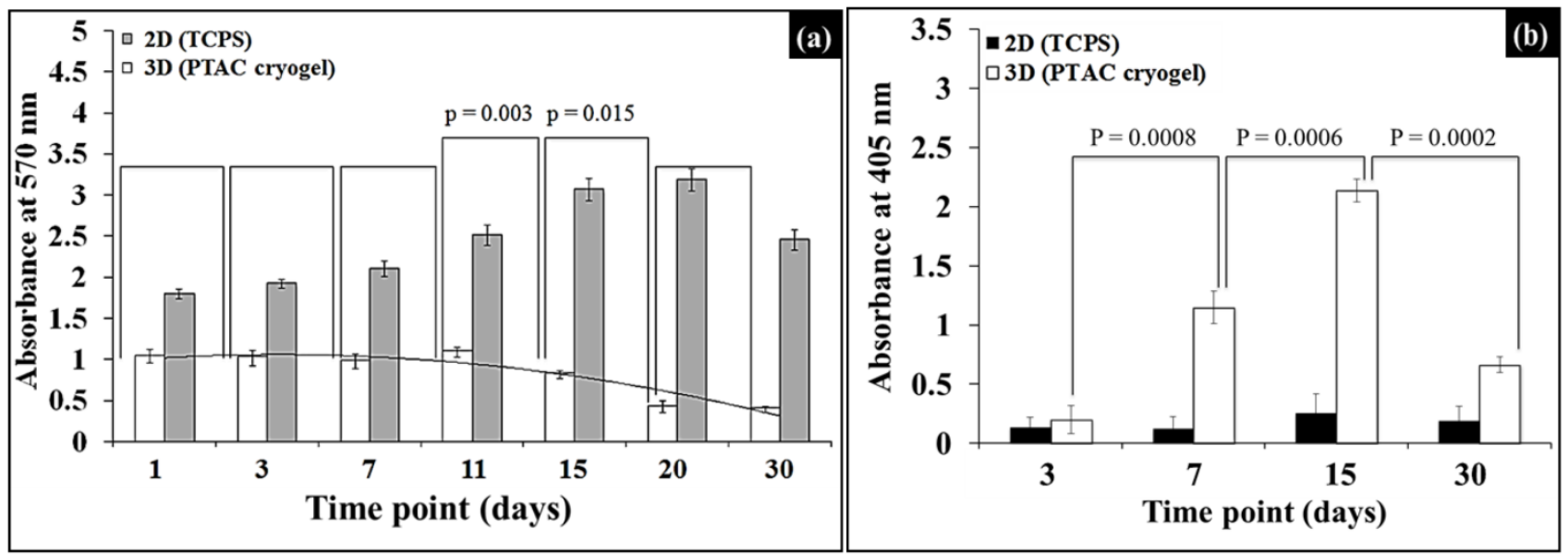

Fig. 1: Cell proliferation and alkaline phosphatase activity of $\mathrm{C} 2 \mathrm{C} 12$ cells sedded on PTAC biocomposite cryogels. (a) Proliferation of $\mathrm{C} 2 \mathrm{C} 12$ cells on the PTAC biocomposite cryogels with respect to two-dimensional (2D) positive control via MTT assay. (b) ALP assay comparing the level of ALP in (2D) tissue cultured polystyrene (TCPS) control with respect to PTAC biocomposite cryogels. 


\section{Scanning electron microscopic (SEM) analysis}

As observed in the case of Fig. 2(a), the cells attained a flattened morphology along with a lot of extracellular matrix (ECM) production but no signs of mineral crystal formation at day 3 while calcium-phosphate like crystals started forming at day 7 as seen in Fig. 2(b) but their number was very few at this timepoint. In Fig. 2(c), i.e., at highest time point of day 30 , the number of these crystals was high, also, these accumulations of crystals were covered with a thick layer of extracellular matrix representing the mineralization phase during osteoblast maturation.

\section{Electron dispersive X-ray spectroscopic (EDX) characterization}

The phenomena occurring on the biocomposite cryogel surface were further confirmed by EDX analysis as can be observed in table 1 . The surface adjacent to cell group contained mainly the characteristic peaks corresponding to the elements of the native material, i.e., carbon, oxygen, calcium and silicon. The areas where cells were attached, i.e., cell surface, at the initial timepoints of day 3, mainly contained strong peaks of carbon and oxygen representing high amount of organic matter corresponding to the cells along with some background interference of the elements of the biocomposite cryogels. This is mainly because the cell layer was still not covered with thick extracellular matrix but at later timepoints as the cells start proliferating and produce a lot of extracellular matrix, only strong carbon and oxygen peaks were observed corresponding to high amount of organic matter present at that area. At day 30, the EDX analysis of extracellular matrix covered calcium-phosphate like crystals represented corresponding peaks including carbon and oxygen correlating with the extracellular matrix, while, calcium and phosphorus act as the characteristic peaks for calcium-phosphate like crystals.

Table 1: Electron dispersive X-ray spectroscopic analysis of different areas on the $\mathrm{C} 2 \mathrm{C} 12$ seeded PTAC biocomposite cryogel surface.

\begin{tabular}{|c|c|c|c|c|c|}
\hline $\begin{array}{l}\text { Area of EDX } \\
\text { analysis }\end{array}$ & $\begin{array}{l}\text { Carbon } \\
\text { (Wt. \%) }\end{array}$ & $\begin{array}{l}\text { Oxygen } \\
\text { (Wt. \%) }\end{array}$ & $\begin{array}{c}\text { Phosphorous } \\
\text { (Wt. \%) }\end{array}$ & $\begin{array}{c}\text { Calcium } \\
\text { (Wt. \%) }\end{array}$ & $\begin{array}{l}\text { Silicon } \\
\text { (Wt. \%) }\end{array}$ \\
\hline $\begin{array}{l}\text { Surface adja- } \\
\text { cent to cell } \\
\text { group }\end{array}$ & $4.82 \pm 0.10$ & $11.56 \pm 0.75$ & - & $4.68 \pm 0.67$ & $25.61 \pm 0.76$ \\
\hline Cell surface & $41.42 \pm 1.32$ & $20.74 \pm 1.45$ & - & $2.25 \pm 0.20$ & $6.21 \pm 0.41$ \\
\hline $\begin{array}{l}\text { Cell surface+ } \\
\text { Thick ECM }\end{array}$ & $47.25 \pm 1.64$ & $34.91 \pm 1.63$ & - & - & - \\
\hline $\begin{array}{l}\text { ECM covered } \\
\text { Ca-phosphate } \\
\text { like crystals }\end{array}$ & $24.32 \pm 0.90$ & $30.61 \pm 1.47$ & $7.20 \pm 0.44$ & $9.79 \pm 0.48$ & - \\
\hline
\end{tabular}

\section{In vivo bone formation in a bone conduction chamber model}

\section{Histological analysis}

Fig. 3(a) and (b) represents the H\&E stained neo-tissue constructs harvested after 24 days at increasing magnifications. New bone formation on the cryogels scaffolds can be observed as early as 24 days of sub-cortical implantation. Fig. 3(a) provides an overview of bone formation with new bone marked as B. Image $3(b)$ provides a further insight into the anatomy of cells present in the newly formed bone matrix. The more bone specific staining using a combination of alcian blue, hematoxylin, orange $g$, phloxine b, eosin is indicated in Fig. 3(c) and (d). The orange stain observed in image (c) and (d) confirms the presence of a mature bone matrix indicated by $\mathrm{B}$. We have not observed the presence of any osteoclasts in the new-formed bone matrix. Moreover, the presence of cells associated with allergy or immunogenicity of foreign materials has not been seen.
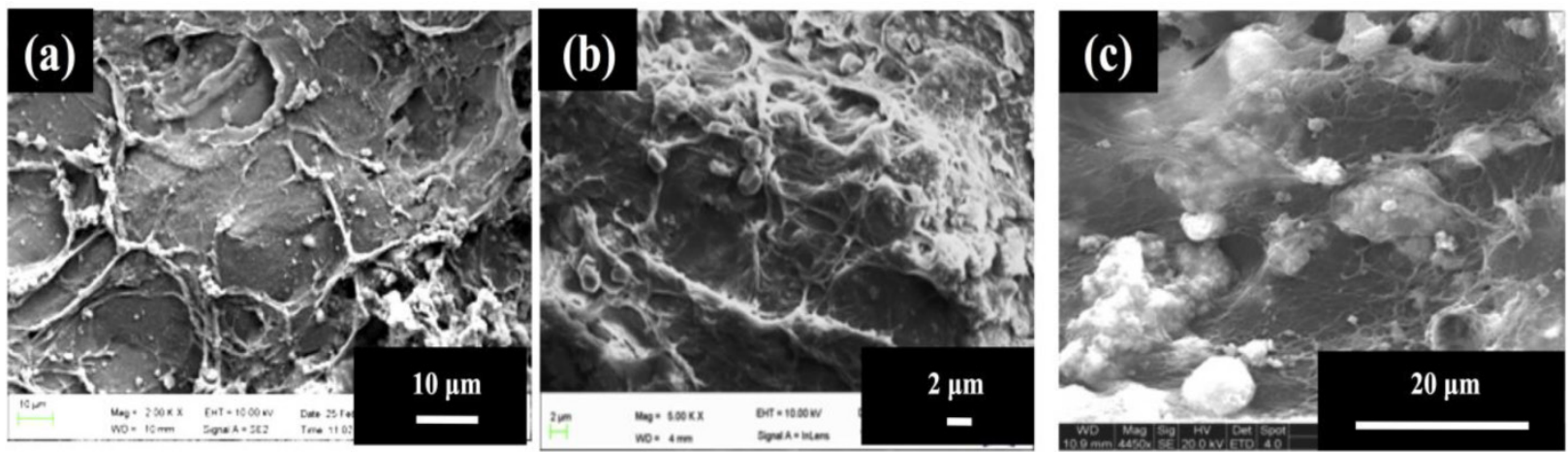

Fig. 2: $\mathrm{C} 2 \mathrm{C} 12$ cell adhesion studies on PTAC biocomposite cryogels. (a) shows cell attachment and (b, c) depict mineralization of $\mathrm{C} 2 \mathrm{C} 12$ cells seeded on PTAC biocomposite cryogels after 3,7 and 30 days of cell seeding, respectively. 


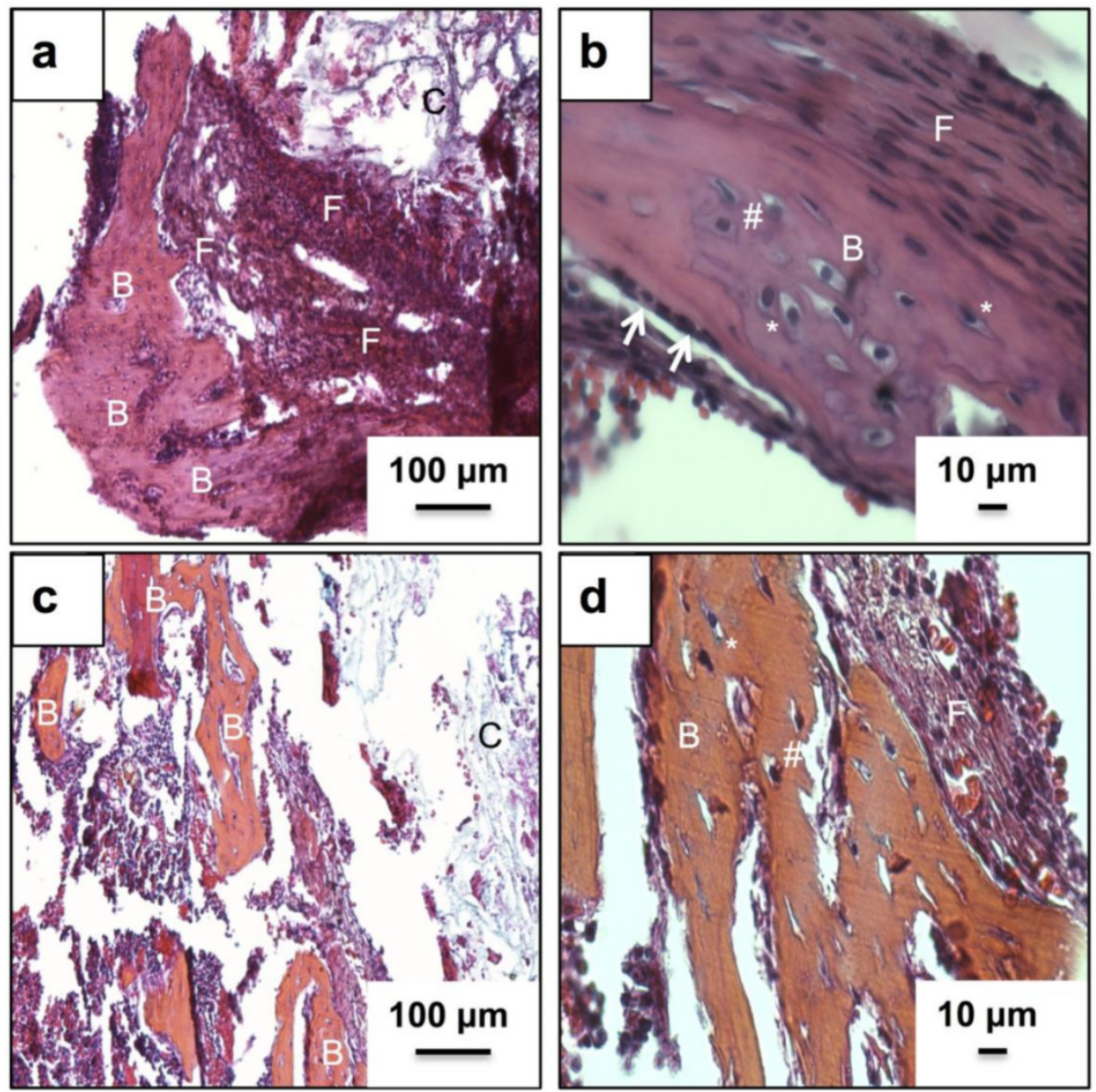

Fig. 3: Histological analysis of neo-tissue construct after 24 days of implantation using H\&E and a bone specific H\&E, alcian blue, orange $g$ and phloxine $b$ mixture. Images $(a, b)$ show H\& E staining while images (c, d) show staining of the neo-tissue using H\& E mixture. Arrows indicate lining osteoblasts, B indicates neo-bone, $F$ shows fibrous tissue, * represents mature osteocytes while, \# indicates immature osteocytes and C shows PTAC biocomposite cryogel scaffold. Images (a, c) have been taken at $100 \mathrm{X}$ and images $(\mathrm{b}, \mathrm{d})$ have been taken at $400 \mathrm{X}$.

\section{Alizarin red staining for neo tissue mineralization}

As seen in Fig. 4, the mineralized regions produced more intense shades of orange providing an indirect clue towards osteogenic cell presence. We have observed calcium in the newly synthesized bone matrix as indicated by Fig. 4(a), and (b). Fig. 4(a) provides an overview of calcium distribution across the scaffold with varying intensity. While mature regions stained positive (Fig. 4(b)) (black arrow), immature regions (white arrow) have higher staining intensity due to higher mineralization activity as seen from Fig. 4(b). Fig. 4(c) indicates mineralization in the implanted scaffold with very less bone formation. Fig. 4(d) shows unimplanted control.

\section{Immunohistochemical analysis for osteogenic markers}

Fig. 5 represents immunostaining of the neo tissue harvested after 24 days of culture. Bone cells in the new bone matrix stained positive (dark brown color) for most abundant bone matrix proteins Col I, OCN, OPN and BSP, as indicated in Fig. 5 (a), (b), (c), and (d), respectively. The expression of bone markers has been observed in some of the cells of the neo bone (indicated by white arrows), the bone matrix and also a prominent dark brown color towards the interface region (red arrows) confirming the presence of neo bone. Panels in the inset represent cells at higher magnification (400X) with strong pericellular staining of bone markers.

\section{Osteogenic differentiation of murine mesen- chymal stem cells on PTAC biocomposite cryogel surface in presence/absence of elec- trical stimulation}

\section{MTT assay}

As observed in Fig. 6(a), the MTT assay showed a similar trend of mesenchymal stem cells (MSCs) proliferation for both electrically stimulated and unstimulated cryogels without any statistically significant difference between the two groups at all time points. Initially the cell proliferation increased until the time point of day 7 and decreased thereafter until 
day 30. Therefore, cell proliferation was not affected by electrical stimulation of the murine mesenchymal stem cells cultured on these cryogels.

\section{Alkaline phosphatase (ALP) assay}

The ALP enzyme was present in highest amount at the first time point, i.e., day 3 and thereafter it followed a serially decreasing trend until day 30 time point in both the electrically stimulated and unstimulated cryogels, as shown in Fig. 6(b). We observed a statistically significant difference for the unstimulated cryogel, and non-significant statistical difference for electrically simulated cryogels, between two consecutive time points. Similarly, when we tried to compare the absorbance values for two methods at different time points, we don't see any statistically significant difference in values except at timepoint day 30 $(p=0.003)$ (two way ANOVA). Thus, ALP enzyme was produced by osteogenic differentiation of murine mesenchymal stem cells in the both unstimulated and stimulated cryogels and this ALP production does not differ much between two methods in intial stages until day 30 time point was reached.

\section{Real time PCR (q-PCR) analysis}

As seen in Fig. 6(c), the electrically stimulated MSCs on the PTAC biocomposite cryogel surface showed $\sim 6$ fold higher collagen I and $\sim 10$ fold higher osteopontin production as compared to the unstimulated cells at day 30 . Here, collagen type I acts as a representative of an early osteogenic marker, whereas, osteopontin acts as a late osteogenic marker.

\section{Cell adhesion via scanning electron microscopy anal- ysis}

Cell adhesion on the PTAC cryogel surface with and without electrical stimulation was analysed via scanning electron microscopy. As observed in Fig. 7, the murine mesencymal stem cells depicted a difference in cell adhesion behaviour on the stimulated and unstimulated cryogel surfaces. At the time point of day 3 and day 7, the cells on the electrically stimulated cryogels showed highly flattened morphology, whereas, the unstimulated cryogels showed cells present as rounded/nodular structures.

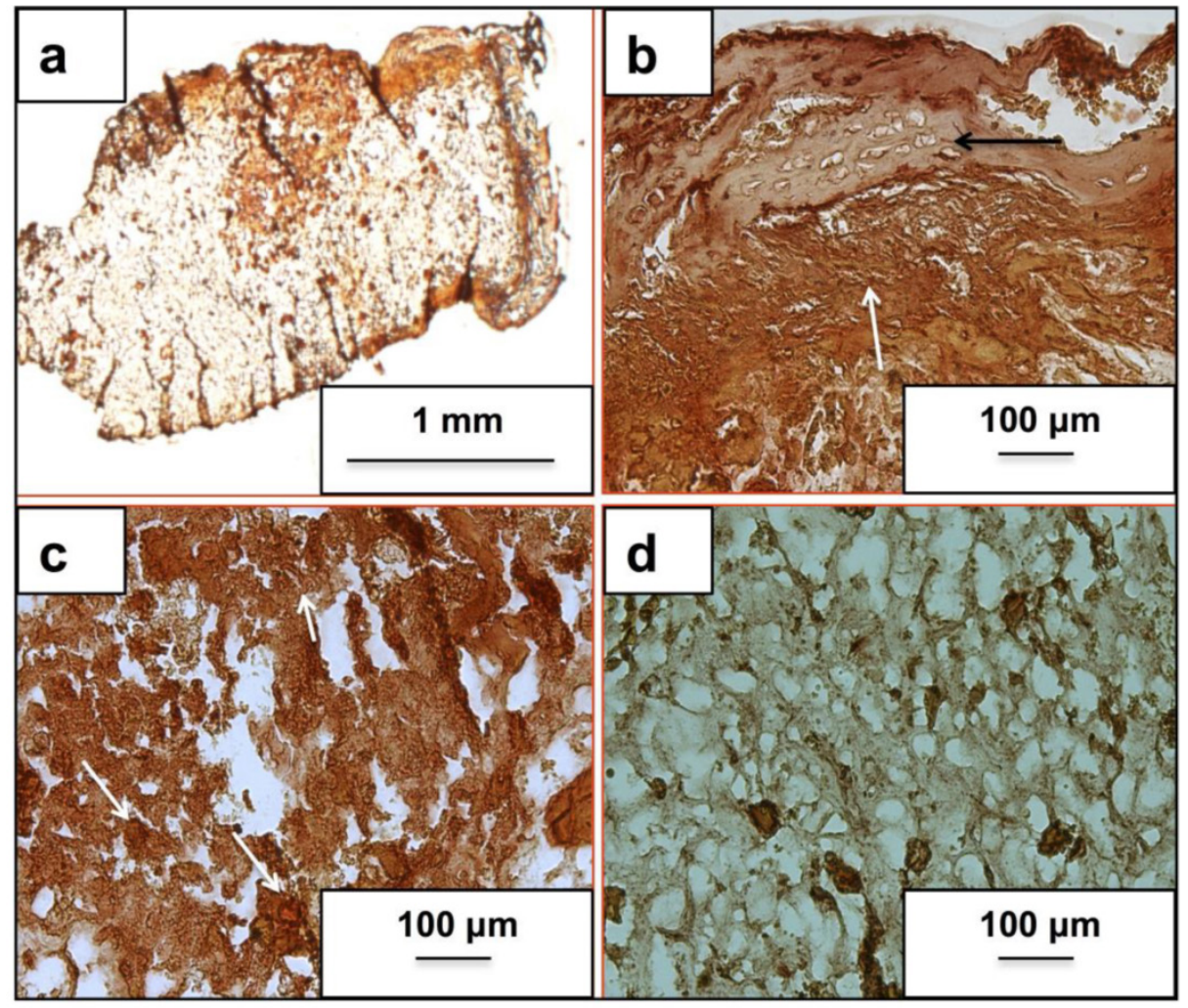

Fig. 4: Alizarin red staining for matrix calcium deposition. Images (a-c) represent calcium deposition in the neo-tissue after 24 days of implantation using the bone conduction chamber. Image (d) indicates alizarin staining in the cryogel scaffold that was not implanted and acts as a background control. Image (a) is taken at $12.5 X$ while images (b-d) have been captured at 100X. 

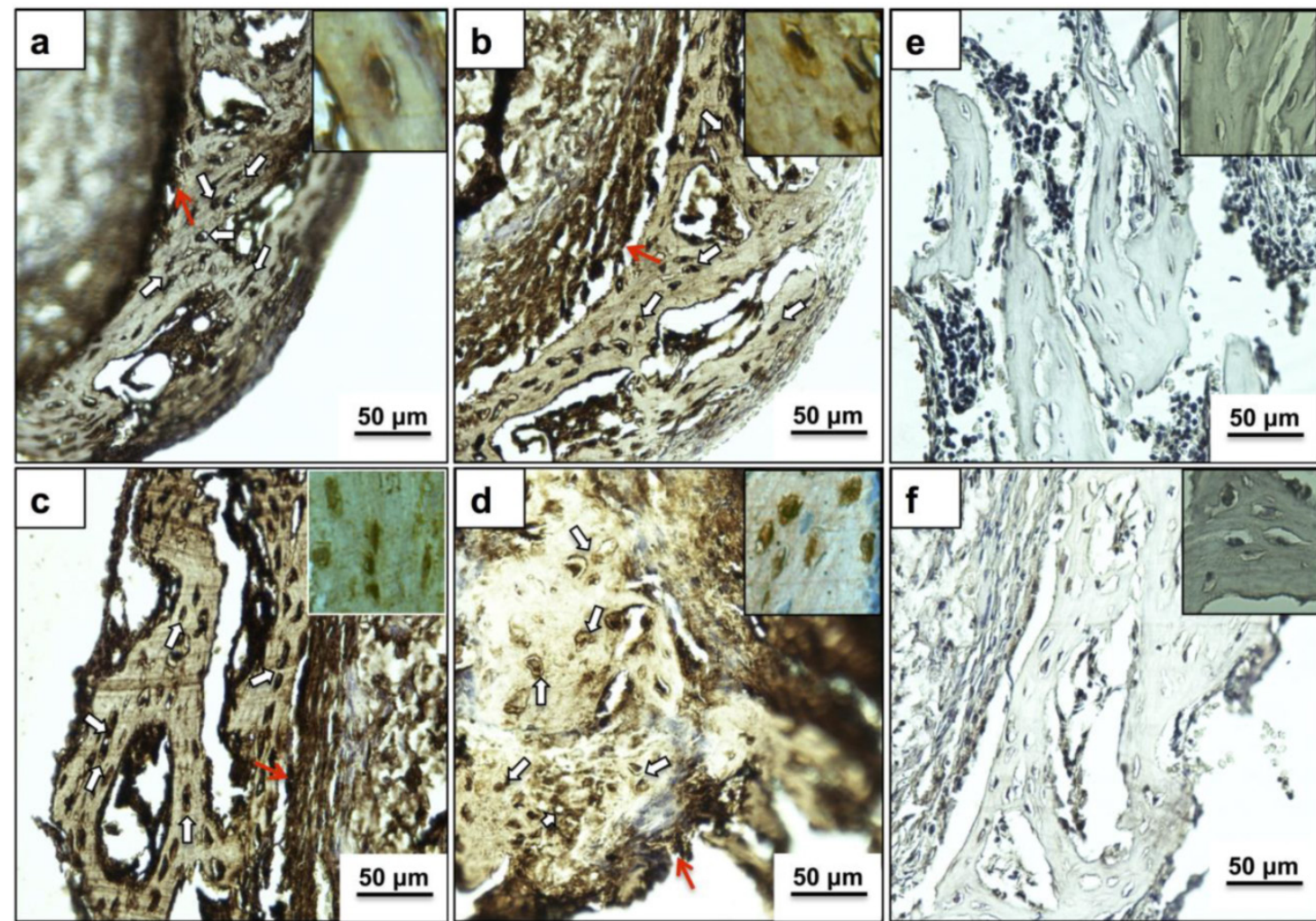

Fig. 5: Immunohistochemical analysis of newly formed bone matrix on PTAC biocomposite cryogel. Images (a-d) indicate cells (white arrows) and matrix staining positive (brown color) for important osteogenic markers like COL I, OCN, OPN and BSP, respectively. Images in inset provide a high magnification insight into the extracellular expression of respective proteins. Images (e) and ( $f$ ) represent the negative antibody controls of anti-mouse and anti-rabbit secondary antibodies, respectively without the addition of a primary antibody. Red arrow shows expression of osteogenic proteins in the interface region. All sections were counterstained with eosin before imaging. All images have been captured at 200X while images in inset are captured at 400X.
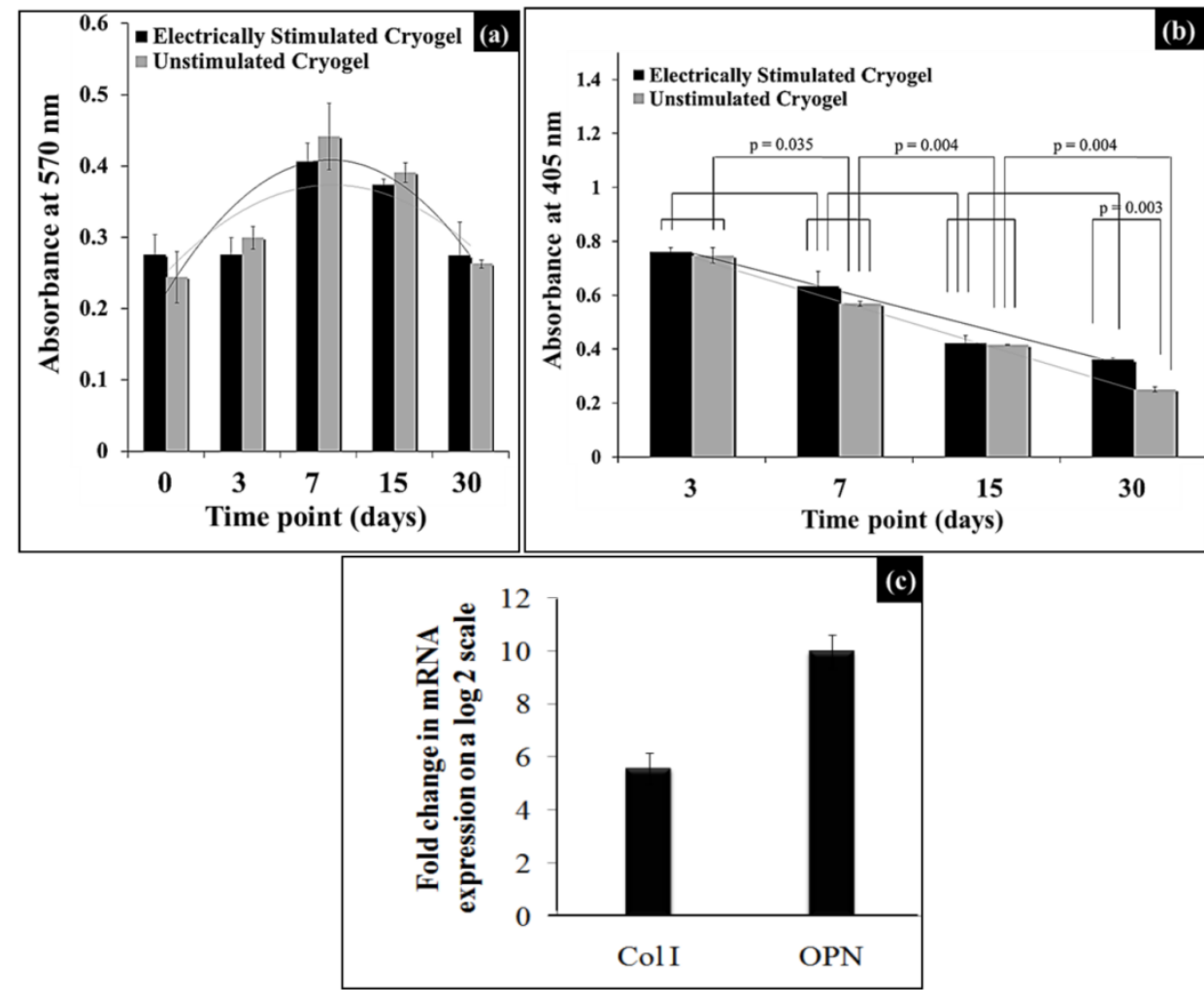

Fig. 6: Effect of electrical stimulation on osteogenic differentiation of mesenchymal stem cells. (a) and (b) show cell proliferation and alkaline phosphatase activity of mesenchymal stem cells seeded on electrically stimulated and unstimulated PTAC biocomposite cyogels. (c) shows the quantitative real-time PCR ( $\mathrm{q}-\mathrm{PCR}$ ) analysis of the fold change increase in mRNA expression of the osteogenic markers, i.e., collagen type I (Col I) and osteopontin (OPN) at day 30 on electrically stimulated cryogels. 

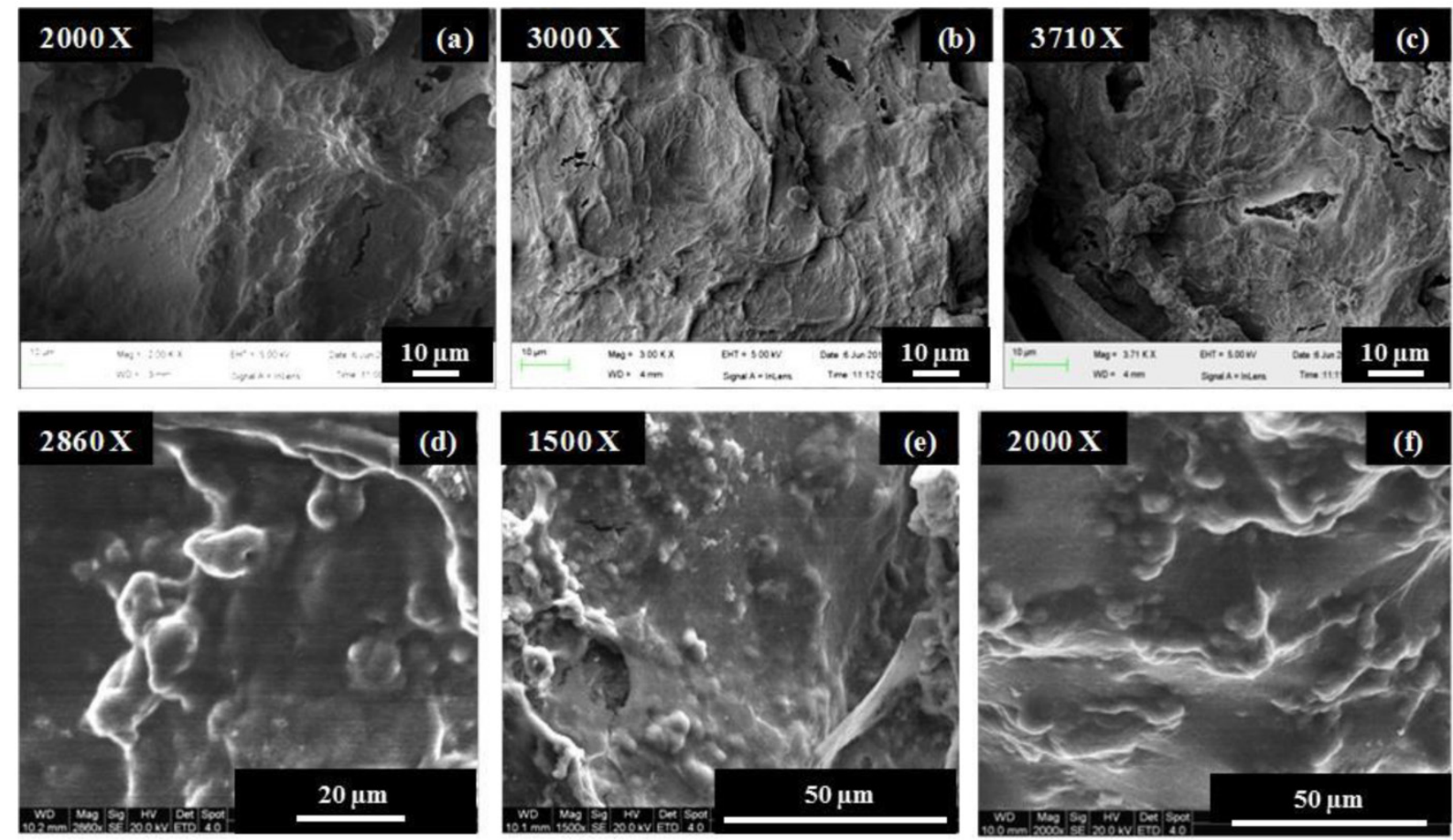

Fig. 7: Murine mesenchymal stem cell adhesion on electrically stimulated and unstimulated PTAC biocomposite cryogels determined via scanning electron microscopy. (a-c) shows the cells seeded on electrically stimulated cryogels at day 3 (a) and day 7 (b, c). (d-f) shows the attachment of cells on unstimulated cryogels at day 3 (d) and day 7 (e, f).

\section{Discussion}

C2C12 myoblast cells have previously been used as precursor cells to study osteogenic differentiation and are a good model for the study of bone differentiation [20]. The MTT assay results (Fig. 1(a)) indicate suppressed proliferation, which can be due to the onset of differentiation. Previous studies have shown that when the cells undergo differentiation their proliferation gets suppressed and they maintain a steady growth. Therefore, the suppression in proliferation of the cells observed in the current results seems to be consistent with the previous studies and suggests that cells may be undergoing differentiation [21-23]. Alkaline phosphatase is an enzyme associated with the osteoblastic activity [24]. Osteoblasts produce this enzyme along with collagen type I during early osteogenic phase. As the osteoblasts proceed towards mineralization, the level of alkaline phosphatase may start declining and osteoblasts start maturing as osteocytes. C2C12 myoblasts do not produce any alkaline phosphatase enzyme on their own, therefore, presence of high ALP assay value confirms the presence of alkaline phosphatase due to osteoblastic activity of osteoblasts formed by the osteogenic differentiation of $\mathrm{C} 2 \mathrm{C} 12$ after being seeded on PTAC cryogels (Fig. 1(b)) [25, 26]. The SEM analysis was performed to determine the behaviour of $\mathrm{C} 2 \mathrm{C} 12$ cells on the surface of PTAC biocomposite cryogels and whether calcium-phosphate like crystals (indicating mineralization) could be observed on the surface of these cryogels over the time (Fig. 2). EDX analysis (table 1) further helped in characterization of the composition of inorganic crystals typically corresponding to apatite formation and organic matter in close proximity to the cells. The production of alkaline phosphatase and formation of extracellular matrix covered with calcium phosphate-like crystals are important indicators of the differentiation of the $\mathrm{C} 2 \mathrm{C} 12$ myoblasts. Therefore, osteoinduction of $\mathrm{C} 2 \mathrm{C} 12$ myoblasts indicates the capability of these cryogels to act as an osteoinductive biomaterial.

The in vivo bone formation on PTAC biocomposite cryogels was performed in a bone conduction chamber model, a widely published model for studying bone remodeling. In most studies, cells of mesenchymal origin from bone marrow infiltrate into the chamber materials. An osteoinductive niche provided by bone grafts leads to maturation of mesenchymal cells into osteogenic cells $[19,27]$. In a novel experiment, we used the above-mentioned hypothesis to assess the bone forming properties of synthesized PTAC cryogel scaffolds in an unloaded bone chamber model. We speculate that mesenchymal cells upon interacting with PTAC cryogels tend to differentiate towards osteogenic lineages due to bone forming properties of bioactive glass, a phenomenon suggested by other scientific groups [11, 28]. Moreover due to the surface topology and controlled pore size, 
there is an efficient exchange of oxygen and other nutrients and growth factors into the matrix, which is an important parameter for osteogenic differentiation [29-31]. Alician blue, hematoxylin, orange g, phloxine-b and eosin stain is more specific for bone and cartilage tissue, wherein, bone produces a bright orange to red color [32]. Osteocytes with typically characterized visible lacunae were also observed (Fig.3 (b) and (d)). The structure of cells organized in the neo tissue resembles that of a mineralized tissue with bone formation [33]. We have not observed the presence of GAG moieties in the new bone matrix or the cryogel scaffold, which suggests that the bone formation in the chamber model with cryogel based matrix undergoes intramembranous ossification. Osteoinductivity of materials is often characterized via mineral deposition [34]. We have observed mineralization in the implanted cryogel matrix and neo tissue constructs after 24 days of in vivo implantation also fitting well with in vitro experiments (Fig. 4). The bioactivity of the scaffold leads to deposition of apatite on the scaffold and thus strong alizarin staining is seen in different parts of the scaffold (Fig. 4(a)-(c)). The mesenchymal cells infiltrating from the underlying bone interact with the precipitated apatite and thus form neo bone tissue within the biocomposite cryogel (Fig 4(b)) placed in the bone chamber. Areas of the scaffold farther from the chamber holes (areas with low or no bone formation) also stain positive due to the phenomenon of apatite deposition (Fig. 4(c)). Unimplanted cryogel scaffold (control) showed slight background staining due to the presence of calcium in the scaffold (Fig. 4(d)). Immunohistochemical analysis revealed the presence of prominent bone markers (Fig. 5). Col I is one of the major components of organic bone matrix while OCN, OPN and BSP are very important markers of bone tissue as they control the anchoring of calcium and phosphate ions thereby controlling the mineral deposition. In the present work, we have found all four mentioned markers in what we have designated as mature bone matrix and also around the neighboring interface lined by osteoblasts. The expression of important bone specific markers at a short interval of time also indicates bone-forming properties of PTAC cryogel scaffolds.

Electrical stimulation has been previously shown to support osteogenesis [35]. Therefore, we also studied the synergistic effects of PTAC biocomposite cryogel and electrical stimulation during osteogenic differentiation of murine mesenchymal stem cells. Cells generally showed similar trends of cell proliferation along with alkaline phosphatase production in the case of both electrically stimulated and unstimulated cryogels indicating towards bone differentiation (Fig. 6(a) and (b)). Although, the mRNA expression of osteogenic markers such as Collagen type I and osteopontin was higher in the electrically stimulated cryogels depicting the synergistic/positive effect of electrical stimulation on bone differentiation of murine mesenchymal stem cells on PTAC biocomposite cryogels.

\section{Conclusion}

Therefore, in this study we found that PTAC cryogels show osteoinductive and osteoconductive properties both during in vitro studies on $\mathrm{C} 2 \mathrm{C} 12$ myoblast's osteogenic differentiation and in vivo analysis of bone formation in a bone conduction chamber model. Another independent study on the effect of electrical stimulation on the osteogenic differentiation of murine mesenchymal stem cells cultured on PTAC biocomposite cryogels suggests synergistic effect of electrical stimulation and cryogels to promote osteogenic differentiation. Hence, the results from the in vitro and in vivo studies clearly indicate the osteogenic potential of PTAC biocomposite cryogels.

\section{Supplementary Material}

Supplementary Figure 1.

http://www.ijbs.com/v11p1325s1.pdf

\section{Acknowledgements}

We acknowledge Department of Biotechnology (DBT), Ministry of Science and Technology, Govt. of India for financial support. AK acknowledges DBT for TATA innovation fellowship. RM thanks IITK for doctoral fellowship. We thank the foundation for the assistance of disabled people in Skåne and the Faculty of Medicine, Lund University for financial support.

\section{Author Contributions}

RM performed in vitro experiments in consultation with AK. MT, MP and DBR performed in vivo study. AK, LL and MT conceived and designed the study. DBR and RM wrote the first draft. All authors contributed in revising the manuscript. All authors approve the final article.

\section{Conflict of Interest}

LL is a board member of Bone Support AB, Lund, Sweden and Orthocell, Australia. All others declare no conflict of interest.

\section{References}

1. Jimi E, Hirata S, Osawa K, Terashita M, Kitamura C, Fukushima H. The current and future therapies of bone regeneration to repair bone defects. Int J Dent. 2012; 2012:7.

2. Amini $A R$, Laurencin $C T$, Nukavarapu SP. Bone tissue engineering: recent advances and challenges. Crit Rev Biomed Eng. 2012; 40:363-408.

3. Bao CLM, Teo EY, Chong M, Liu Y, Choolani M, Chan J. Advances in bone tissue engineering. In: Andrades JA, ed. Regen Med Tissue Eng. Rijeka: Intech. 2013:599-614. 
4. Johnson EO, Troupis T, Soucacos PN. Tissue-engineered vascularized bone grafts: Basic science and clinical relevance to trauma and reconstructive microsurgery. Microsurg. 2011;31: 176-82.

5. Li C, Vepari C, Jin H-J, Kim HJ, Kaplan DL. Electrospun silk-BMP-2 scaffolds for bone tissue engineering. Biomaterials. 2006; 27: 3115-24.

6. Langer R, Vacanti J. Tissue engineering. Science. 1993; 260: 920-6.

7. Friedenstein A. Induction of bone tissue by transitional epithelium. Clin Orthop Rel Res. 1968; 59: 21-38.

8. Barradas A, Yuan H, Blitterswijk CA, Habibovic P. Osteoinductive biomaterials: current knowledge of properties, experimental models and biological mechanisms. Eur Cell Mater. 2011; 21: 407-29.

9. Frohlich M, Grayson WL, Wan LQ, Marolt D, Drobnic M, Vunjak-Novakovic G. Tissue engineered bone grafts: biological requirements, tissue culture and clinical relevance. Curr Stem Cell Res Ther. 2008; 3: 254-64.

10. Jones JR. Review of bioactive glass: from Hench to hybrids. Acta Biomater. 2013; 9: 4457-86.

11. Mishra R, Kumar A. Inorganic/organic biocomposite cryogels for regeneration of bony tissues. J Biomater Sci, Polym Ed. 2011; 22: 2107-26.

12. Mishra R, Goel SK, Gupta KC, Kumar A. Biocomposite cryogels as tissue-engineered biomaterials for regeneration of critical-sized cranial bone defects. Tissue Eng A. 2013; 20: 751-62.

13. Midha S, Kim TB, van den Bergh W, Lee PD, Jones JR, Mitchell CA. Preconditioned $70530 \mathrm{C}$ bioactive glass foams promote osteogenesis in vivo. Acta Biomater. 2013; 9: 9169-82.

14. Xynos ID, Edgar AJ, Buttery LD, Hench LL, Polak JM. Ionic products of bioactive glass dissolution increase proliferation of human osteoblasts and induce insulin-like growth factor II mRNA expression and protein synthesis. Biochem Biophys Res Comm. 2000; 276: 461-5.

15. Xynos ID, Edgar AJ, Buttery LD, Hench LL, Polak JM. Gene-expression profiling of human osteoblasts following treatment with the ionic products of Bioglass $\AA^{8} 45 S 5$ dissolution. J Biomed Mater Res. 2001; 55: 151-7.

16. Ciombor DM, Aaron RK. The role of electrical stimulation in bone repair. Foot Ankle Clin. 2005; 10: 579-93.

17. Livak KJ, Schmittgen TD. Analysis of relative gene expression data using real-time quantitative PCR and the $2-\triangle \Delta C T$ method. Methods. 2001; 25: 402-8.

18. Jeppsson C, Åstrand J, Tägil M, Aspenberg P. A combination of bisphosphonate and BMP additives in impacted bone allografts. Acta Orthop. 2003; 74: 483-9.

19. Belfrage O, Flivik G, Sundberg M, Kesteris U, Tägil M. Local treatment of cancellous bone grafts with BMP-7 and zoledronate increases both the bone formation rate and bone density: a bone chamber study in rats. Acta Orthop. 2011; 82: 228-33.

20. Yu S, Geng Q, Sun F, Yu Y, Pan Q, Hong A. Osteogenic differentiation of $\mathrm{C} 2 \mathrm{C} 12$ myogenic progenitor cells requires the Fos-related antigen Fra-1-A novel target of Runx2. Biochem Biophys Res Comm. 2013; 430: 173-8.

21. Liu T, Teng WK, Chan BP, Chew SY. Photochemical crosslinked electrospun collagen nanofibers: synthesis, characterization and neural stem cell interactions. J Biomed Mater Res A. 2010; 95: 276-82.

22. Xia K, Xue H, Dong D, Zhu S, Wang J, Zhang Q, et al. Identification of the proliferation/differentiation switch in the cellular network of multicellular organisms. PLoS Comput Biol. 2006; 2: e145.

23. Scott RE, Hoerl BJ, Wille JJ, Florine DL, Krawisz BR, Yun K. Coupling of proadipocyte growth arrest and differentiation. II. A cell cycle model for the physiological control of cell proliferation. J Cell Biol. 1982; 94: 400-5.

24. Malaval L, Modrowski D, Gupta AK, Aubin JE. Cellular expression of bone-related proteins during in vitro osteogenesis in rat bone marrow stromal cell cultures. J Cell Physiol. 1994; 158: 555-72.

25. Katagiri T, Yamaguchi A, Komaki M, Abe E, Takahashi N, Ikeda T, et al. Bone morphogenetic protein-2 converts the differentiation pathway of $\mathrm{C} 2 \mathrm{C} 12 \mathrm{my}-$ oblasts into the osteoblast lineage. J Cell Biol. 1994; 127: 1755-66.

26. Han B, Tang B, Nimni ME. Quantitative and sensitive in vitro assay for osteoinductive activity of demineralized bone matrix. J Orthop Res. 2003; 21: 648-54.

27. Tägil M, Aspenberg P. Cartilage induction by controlled mechanical stimulation in vivo. J Orthop Res. 1999; 17: 200-4

28. Clupper DC, Gough JE, Embanga PM, Notingher I, Hench LL, Hall MM. Bioactive evaluation of $45 \mathrm{~S} 5$ bioactive glass fibres and preliminary study of human osteoblast attachment. J Mater Sci: Mater Med. 2004; 15: 803-8.

29. Kuboki $Y$, Saito T, Murata M, Takita H, Mizuno M, Inoue M, et al. Two distinctive BMP-carriers induce zonal chondrogenesis and membranous ossification, respectively; geometrical factors of matrices for cell-differentiation. Connect Tissue Res. 1995; 32: 219-26.

30. Gauthier O, Bouler J-M, Aguado E, Pilet P, Daculsi G. Macroporous biphasic calcium phosphate ceramics: influence of macropore diameter and macroporosity percentage on bone ingrowth. Biomaterials. 1998; 19: 133-9.

31. Kühne J-H, Bartl R, Frisch B, Hammer C, Jansson V, Zimmer M. Bone formation in coralline hydroxyapatite: effects of pore size studied in rabbits. Acta Orthop. 1994; 65: 246-52.

32. Nowalk JR, Flick LM. Visualization of different tissues involved in endochondral ossification with alcian blue hematoxylin and orange G/eosin counterstain. J Histotechnol. 2008; 31: 19-21.

33. Clarke B. Normal bone anatomy and physiology. Clin J Am Soc Nephrol. 2008; 3: S131-S9.
34. Li W-J, Tuli R, Huang X, Laquerriere P, Tuan RS. Multilineage differentiation of human mesenchymal stem cells in a three-dimensional nanofibrous scaffold. Biomaterials. 2005; 26: 5158-66.

35. Yonemori K, Matsunaga S, Ishidou Y, Maeda S, Yoshida H. Early effects of electrical stimulation on osteogenesis. Bone. 1996; 19: 173-80. 